\title{
Effect of Type I Diabetes on the Proteome of Mouse Oocytes
}

\author{
Guangjian Jiang ${ }^{a}$ Guangli Zhang ${ }^{a}$ Tian An ${ }^{a}$ Zhongchen $\mathrm{He}^{c}$ Lihua Kang ${ }^{c}$ \\ Xiuyan Yang ${ }^{a}$ Yujie Gua Dongwei Zhanga Yangang Wang ${ }^{b}$ Sihua Gao ${ }^{a}$ \\ aDiabetes Research Center, Beijing University of Chinese Medicine, Beijing, ${ }^{b} \mathrm{Hebei}$ Provincial Hospital \\ of Traditional Chinese Medicine, Shi Jia Zhuang, 'Endocrine Department, Beijing He ping li Hospital, \\ Beijing, China
}

\section{Key Words}

Oocyte $\cdot$ Type I diabetes $\cdot$ Histone variant $\cdot$ Metabolism $\bullet$ Streptozotocin

\begin{abstract}
Background: Type I diabetes is a global public health concern that affects young people of reproductive age and can damage oocytes, reducing their maturation rate and blocking embryonic development. Understanding the effects of type I diabetes on oocytes is important to facilitate the maintenance of reproductive capacity in female diabetic patients. Methods: To analyze the effects of type I diabetes on mammalian oocytes, protein profile changes in mice with streptozotocin-induced type I diabetes were investigated using proteomic tools; nondiabetic mouse oocytes were used as controls. Immunofluorescence analysis for the spindle and mitochondria of oocytes. Results: We found that type I diabetes severely disturbed the metabolic processes of mouse oocytes. We also observed significant changes in levels of histone $\mathrm{H} 1, \mathrm{H} 2 \mathrm{~A} / \mathrm{B}$, and $\mathrm{H} 3$ variants in diabetic oocytes (fold change: $>0.4$ or $<-0.4$ ), with the potential to block activation of the zygotic genome and affect early embryo development. Furthermore, diabetic oocytes exhibited higher abnormal spindle formation and spatial remodeling of mitochondria than observed in the controls. Conclusion: Our results indicate that type I diabetes disrupts metabolic processes, spindle formation, mitochondria distribution and modulates epigenetic code in oocytes. Such effects could have a major impact on the reproductive dynamics of female patients with type I diabetes.
\end{abstract}

\section{Introduction}

Gestational diabetes mellitus (GDM) is a risk factor for pregnancy-related maternal and fetal morbidity [1]. Previous studies have shown that type I diabetes can severely decrease mammalian oocyte quality. Diabetic mouse oocytes contain more mitochondrial DNA and 


\section{Cellular Physiology Cell Physiol Biochem 2016;39:2320-2330 \begin{tabular}{l|l|l} 
and Biochemistry $\begin{array}{l}\text { DOI: 10.1159/000447924 } \\
\text { Published online: November 07, } 2016\end{array}$ & $\begin{array}{l}\text { (c) } 2016 \text { The Author(s). Published by S. Karger AG, Basel } \\
\text { www.karger.com/cpb }\end{array}$
\end{tabular} \\ Jiang et al.:Effect of Type I Diabetes on Mouse Oocytes and Protein Profile Changes}

exhibit greater transcription of mitochondrial genes than non-diabetic mouse oocytes [2], and oocyte maturation and ovulation rates are considerably lower than those of controls [3]. Ovulated oocytes from diabetic mice can be fertilized; however, the majority of embryos from diabetic mice cannot develop to the blastocyst stage [4]. A recent report demonstrated that type I diabetes can alter the expression of DNMT1, which is associated with DNA methylation [5], another study showed that certain lncRNAs might play a role in GDM macrosomia development[6]. This indicates that GDM may influence epigenetic modification in mouse oocytes. Epigenetics provides a link between environmental factors that have been linked to poor pregnancy outcomes and fetal quality [7].

Most maternal mRNAs that accumulate in oocytes have short poly(A) tails and are not translated until the early embryo stage [8]; therefore, transcriptome analysis of type I diabetic oocytes does not reflect actual protein levels, or even mRNA levels, as the poly(A) tail length affects the cDNA synthesis rate. Therefore, we used a streptozotocin (STZ)-induced mouse model for proteomic profiling of diabetic mouse oocytes and to characterize how type I diabetes affects mammalian oocyte quality. Elucidation of the landscape of protein modulation in type I diabetic oocytes may facilitate efforts to ameliorate the reproductive defects observed in this disease.

\section{Materials and Methods}

Establishment of a Type I diabetes mouse model and oocyte isolation

All experimental protocols were performed in accordance with relevant guidelines and regulations and approved by Beijing University of Chinese Medicine, China. ICR female mice (6-7 weeks old) were used for our experiments. The type I diabetes mouse model was established by intraperitoneal injection of STZ as described by Bonnevie-Nielsen [9]. Four days after STZ (STZ-Na-citrate solution) injection, glucose concentrations were measured in tail blood samples using an Accu-CHEK active glucometer (Roche Diagnostics). Mice with glucose levels $>16.7 \mathrm{mmol} / \mathrm{L}(\mathrm{n}=72)$ were selected as diabetic model animals. Control mice $(n=66)$ were injected with an equivalent volume of Na-citrate solution and their blood sugar level was checked to ensure that it was $<8.4 \mathrm{mmol} / \mathrm{L}$.

Diabetic mice and age-matched controls were injected intraperitoneally with 10 IU of pregnant mare serum gonadotropin (PMSG) for ovarian follicle stimulation. After 48 h, 10 IU of human chorionic gonadotropin (hCG) was injected to induce superovulation. Cumulus oocyte complexes (COCs) were isolated from diabetic and control mice $14 \mathrm{~h}$ after hCG injection. COCs were treated with $1 \mathrm{mg} / \mathrm{mL}$ hyaluronidase, and metaphase II (MII)-stage oocytes were isolated, We showed the above protocol by visual representation [10] (Fig. 1). In total, 2020 and 1094 oocytes were isolated from 66 and 72 control and diabetic mice, respectively, for proteomic analysis.

\section{Proteome profiling of mouse oocytes}

The isobaric tags for relative and absolute quantitation (iTRAQ) method was used to quantify proteins expressed in control and diabetic mouse oocytes as previously described [11]. After high-performance liquid chromatography and mass spectrometry analyses, Proteome Discoverer (version 1.3) was used to analyze the proteome data.

\section{Western blotting}

Allantibodies used forwestern blotvalidation were purchased from Proteintech. The primaryantibodies used were rabbit anti-HIST1H3D (20532-1-AP, 1:500), rabbit anti-NNT (13442-2-AP, 1:500), rabbit antiPGK2 (13686-1-AP, 1:1000), rabbit anti-HIST2H2AA4 (15302-1-AP, 1:500), rabbit anti-GSS (15712-1-AP, 1:500), and mouse anti-GAPDH (60004-1-Ig, 1:10,000). Secondary antibodies were peroxidase-conjugated Affinipure goat anti-mouse IgG (H+L) (SA00001-1, 1:5000) and peroxidase-conjugated Affinipure goat anti-

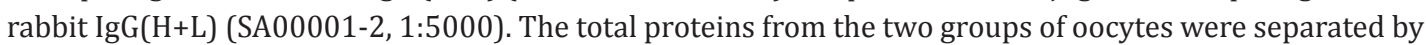
SDS-PAGE and then transferred to polyvinylidene fluoride membranes. Subsequently, the membranes were washed, blocked, and incubated with the primary antibodies for $2 \mathrm{~h}$ at $25^{\circ} \mathrm{C}$. The membranes were washed three times, incubated with the respective secondary antibody, and washed another three times. Western 


\section{Cellular Physiology Cell Physiol Biochem 2016;39:2320-2330

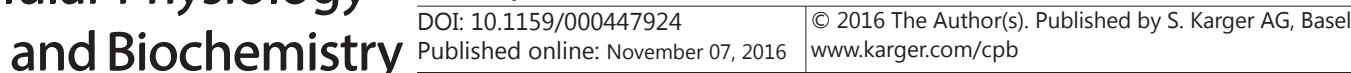

Fig. 1. Timeline of maturation of oocytes. For in vivo maturation of oocytes, follicle maturation was stimulated by PMSG on day 0 (control group) and four days after STZ injection (diabetic group). Ovulation was induced by hCG $48 \mathrm{~h}$ later. Oocytes were collected from the ampullae $14 \mathrm{~h}$ after hCG injection.

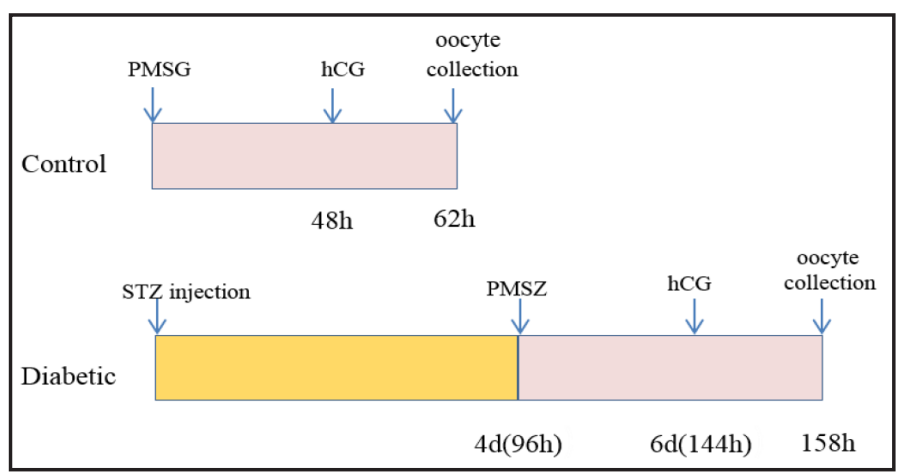

blots were visualized using enhanced chemiluminescence reagents (Santa Cruz Biotech). ImageJ was used for semi-quantification of protein levels.

Proteome data analysis

To identify differentially expressed proteins (DEPs) in diabetic oocytes, we calculated the $\log 2$ ratio of protein content in diabetic and normal oocytes (log2(STZ/Normal)). Values of log2(STZ/Normal) $>0.4$ or $<0.04$ in diabetic oocytes were considered to indicate up- or down-regulated proteins, respectively. To visualize the effects of DEPs on oocyte metabolic processes, we combined protein-protein interaction data from Reactome [12] and metabolism data from Biowarehouse [13], and we visualized DEPs using Cytoscape [14]. Gene location data were obtained from the UCSC Genome Bioinformatics website (http://genome. ucsc.edu/). All scripts used for data analysis are available on request.

Spindle and chromosome staining in oocytes

For spindle and chromosome analysis, 54 oocytes from diabetic mice and 58 oocytes from control mice were collected and fixed in 4\% paraformaldehyde in PBS for $30 \mathrm{~min}$, and then permeabilized in $0.5 \%$ Triton X-100 at room temperature for $20 \mathrm{~min}$. Next, the oocytes were blocked in $1 \%$ bovine serum albumin in PBS for $1 \mathrm{~h}$, followed by incubation for $2 \mathrm{~h}$ at room temperature with fluorescein isothiocyanateconjugated $\beta$-tubulin antibody (1:300) to visualize the microtubules in the spindles. After washing three times in PBS containing 1\% Tween-20 and 0.01\% Triton X-100, the oocytes were stained with $10 \mu \mathrm{g} / \mathrm{mL}$ propidium iodide for $10 \mathrm{~min}$. Finally, the oocytes were mounted on glass slides and viewed under a confocal laser scanning microscope (Zeiss LSM 710).

\section{Immunofluorescence analysis of mitochondria}

For staining of the mitochondrial and inner mitochondrial membrane potential, 53 oocytes from the control group and 50 oocytes from the diabetic group were cultured in M2 medium containing $200 \mathrm{nM}$ Mito-Tracker Red for $30 \mathrm{~min}$ at $37^{\circ} \mathrm{C}$ in a $5 \% \mathrm{CO} 2$ atmosphere. After staining was complete, the solution was replaced with fresh M2 medium, and oocytes were stained with $10 \mu \mathrm{g} / \mathrm{mL}$ Hoechst 33342 for $10 \mathrm{~min}$. Finally, oocytes were mounted on glass slides and viewed under a confocal laser scanning microscope (Zeiss LSM 780).

\section{Statistical analysis}

Fisher's exact test was used to determine the statistical significance of differences between normal and diabetic oocytes, with $\mathrm{p}<0.01$ considered as indicative of statistical significance.

\section{Results}

Proteins differentially expressed between diabetic and normal oocytes

Using proteomic profiling, we identified 3521 proteins in diabetic and control mouse oocytes (for online supplementary material, see www.karger.com/doi/10.1159/000447924), of which 82 were downregulated and 70 were upregulated in oocytes from diabetic mice (see supplementary material). Five DEPs were selected (PGK2, HIST2H2AA4, GSS, NNT, and 


\section{Cellular Physiology Cell Physiol Biochem 2016;39:2320-2330

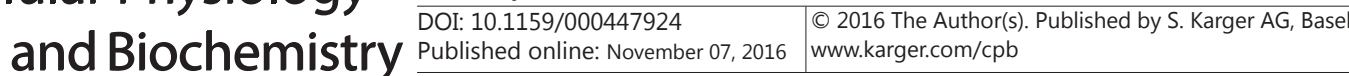 \\ Jiang et al.:Effect of Type I Diabetes on Mouse Oocytes and Protein Profile Changes}

Fig. 2. Western blot validation of proteome profiling results. PGK2, phosphoglycerate kinase 2; HIST2H2AA4, histone H2A.2; GSS, glutathione synthetase; NNT, NAD(P) transhydrogenase, mitochondrial; HIST1H3D (HIST1H3A in mouse), histone H3.1 of humans or mice; GAPDH (loading control), glyceraldehyde-3-phosphate dehydrogenase.

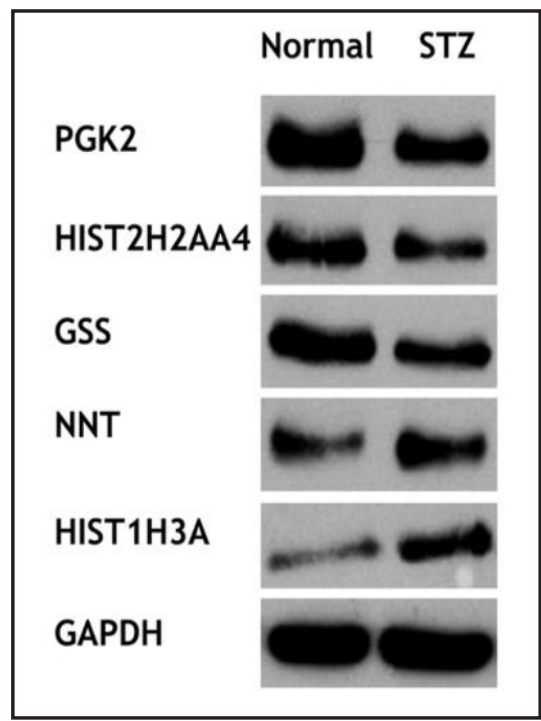

Fig. 3. Consistency of the iTRAQ data and western blot data. iTRAQ and western blot for proteins (HIST1H3A, NNT, PGK2, HIST2H2AA4 and GSS ), The western blot results were consistent with the iTRAQ data.

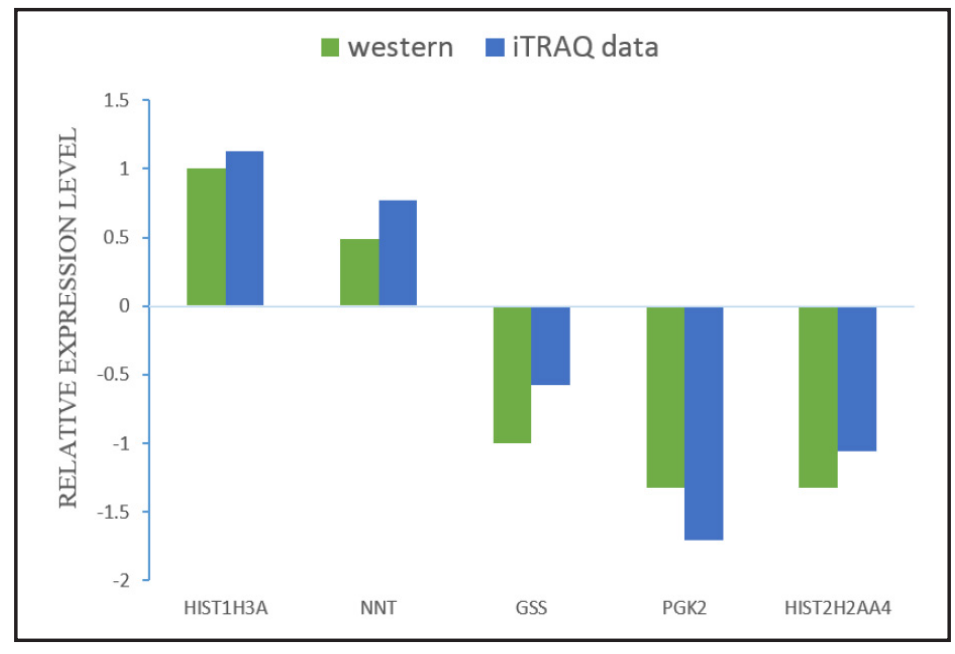

HIST1H3A) for western blot analysis to validate the proteome profiling results. Protein expression patterns evaluated by western blotting were consistent with the proteomics results (Fig. 2, Fig. 3), indicating the accuracy and reliability of the proteomic data.

To analyze the cellular localization of the DEPs and their associated biological processes, we annotated the DEPs using Gene Ontology terms (Tables 1 and 2). Type I diabetes mainly caused upregulation of proteins located in endoplasmic reticulum (ER) and mitochondria; however, downregulated proteins were primarily extracellular (Table 1). In addition, we found that type I diabetes principally influenced oocyte biological processes including transport, oxidation-reduction, lipid metabolism, metabolic processes, nucleosome assembly, proteolysis, and transcription (Table 2).

\section{Effects of diabetes on mouse oocyte metabolism}

In oocytes, mitochondria function in both energy production and maintenance of redox and $\mathrm{Ca} 2+$ homeostasis [15]. Redox status, which determines the level of reactive oxygen species (ROS) in cells, is regulated by three redox couples: reduced and oxidized glutathione (GSH), NADH/NAD+, and NADPH/NADP+ [16]. To determine how type I diabetes influences the various facets of metabolism, we assessed the differentially expressed metabolic enzymes FDXR, NNT, CYB5R3, HSD3B1, and PARP12. FDXR promotes mitochondrial NADPH production in diabetic oocytes (Fig. 4) and may therefore influence metabolite dynamics in diabetic oocyte mitochondria. NNT plays an essential role in proton transfer from NADPH to NAD+ to 


\begin{tabular}{|c|c|c|}
\hline \multirow{2}{*}{$\begin{array}{c}\text { Cellular Physiology } \\
\text { and Biochemistry }\end{array}$} & \multicolumn{2}{|c|}{ Cell Physiol Biochem 2016;39:2320-2330 } \\
\hline & $\begin{array}{l}\text { DOI: } 10.1159 / 000447924 \\
\text { Published online: November 07, } 2016\end{array}$ & $\begin{array}{l}\text { O } 2016 \text { The Author(s). Published by S. Karger AG, Basel } \\
\text { www.karger.com/cpb }\end{array}$ \\
\hline
\end{tabular}

Table 1. Cellular localization of differentially expressed proteins (DEPs)

\begin{tabular}{|c|c|c|c|}
\hline $\begin{array}{l}\text { Cellular } \\
\text { Component }\end{array}$ & $\begin{array}{l}\text { Number } \\
\text { of DEPs }\end{array}$ & Upregulated Proteins & Downregulated Proteins \\
\hline $\begin{array}{l}\text { Apical plasma } \\
\text { membrane }\end{array}$ & 7 & RAB27A, PSEN1, ABCC6, PLET1 & HSPA1A, PFKM, MSN \\
\hline Chromosome & 11 & $\begin{array}{l}\text { TOP1, HIST1H1C, HIST1H1B, HIST1H1A, } \\
\text { H2AFY, HIST1H1E, HIST1H1D, HIST1H3A }\end{array}$ & HIST2H2AB, HIST3H2BA, HIST1H2AH \\
\hline Cytoplasm & 61 & $\begin{array}{l}\text { MARCKS, ACOT13, TCL1, EWSR1, } \\
\text { LRRFIP1, STOM, TGM2, CAST, FGB, } \\
\text { CYB5R3, TOP1, STAT5B, FXN, PLA2G4A, } \\
\text { YBX1, MYO1B, ARF4, CKAP4, CTHRC1, } \\
\text { S100A8 }\end{array}$ & $\begin{array}{l}\text { PGK2, SFN, SERPINB5, ENO3, CPS1, S100A6, KRT7, } \\
\text { KRT18, PSP, CABP7, S100A13, TPM2, FLNC, } \\
\text { HSPA1A, KRT17, TMSB4X, PFKM, CACYBP, PSMA4, } \\
\text { CMTR1, TAF15, RNF126, PRDX6, PDCD4, CAR2, PIR, } \\
\text { HDGF, MSN, ALB, CNOT8, NUCKS1, SRI, LASP1, } \\
\text { NME2, GRCC10, CAPN2, UROD, ITIH4, SHMT1, } \\
\text { DPYSL2, GSTZ1 }\end{array}$ \\
\hline $\begin{array}{l}\text { Cytoplasmic } \\
\text { vesicle }\end{array}$ & 7 & SCAMP5, PSEN1, SYPL, OVGP1, PLA2G4A & VGF, PRDX6 \\
\hline Cytoskeleton & 10 & MARCKS, STOM, CKAP4, S100A8 & TPM2, FLNC, TMSB4X, MSN, LASP1, DPYSL2 \\
\hline Cytosol & 19 & $\begin{array}{l}\text { BCL2L10, TGM2, SCPEP1, STAT5B, FXN, } \\
\text { PLA2G4A }\end{array}$ & $\begin{array}{l}\text { S100A6, S100A13, HSPA1A, TMSB4X, PFKM, PRDX6, } \\
\text { PDCD4, CAR2, SRI, UROD, PTMS, SHMT1, DPYSL2 }\end{array}$ \\
\hline $\begin{array}{l}\text { Endoplasmic } \\
\text { reticulum }\end{array}$ & 13 & $\begin{array}{l}\text { TCL1, PTPLAD1, PSEN1, CTSC, SPCS2, } \\
\text { CYB5R3, LRRC59, SSR3, CDS2, PLA2G4A, } \\
\text { CKAP4, APOC1, HSD3B1 }\end{array}$ & \\
\hline $\begin{array}{l}\text { Extracellular } \\
\text { region }\end{array}$ & 20 & $\begin{array}{l}\text { FGB, SCPEP1, NAPSA, YBX1, APOC1, } \\
\text { CTHRC1, S100A8 }\end{array}$ & $\begin{array}{l}\text { SFN, SERPINB5, S100A13, A1BG, TTR, EDIL3, VGF, } \\
\text { SERPINA3N, IFNB1, APOA2, ALB, PTX3, ITIH4 }\end{array}$ \\
\hline $\begin{array}{l}\text { Extracellular } \\
\text { space }\end{array}$ & 16 & FGB, NAPSA, CTHRC1, S100A8, VNN1 & $\begin{array}{l}\text { SERPINB5, S100A13, TTR, VGF, SERPINA3N, CAR2, } \\
\text { HDGF, IFNB1, APOA2, ALB, PRSS1 }\end{array}$ \\
\hline Golgi apparatus & 9 & $\begin{array}{l}\text { RAB27A, SCAMP5, PSEN1, CTSC, } \\
\text { PLA2G4A, ARF4 }\end{array}$ & KRT7, CABP7, GKAP1 \\
\hline $\begin{array}{l}\text { Integral } \\
\text { membrane } \\
\text { component }\end{array}$ & 24 & $\begin{array}{l}\text { EMC4, ATP5J2, BCL2L10, PTPLAD1, } \\
\text { SCAMP5, PSEN1, SPCS2, SYPL, UNC80, } \\
\text { LRRC59, SSR3, CDS2, ABCC6, CKAP4, } \\
\text { TMEM14C, NNT, VNN1, GRAMD1B, } \\
\text { HSD3B1, TMEM141 }\end{array}$ & VMN2R4, CABP7, GPR1, TMPRSS13 \\
\hline $\begin{array}{l}\text { Intermediate } \\
\text { filament }\end{array}$ & 7 & KRT6A, KRT19 & 4732456N10RIK, KRT7, KRT18, KRT17, NME2 \\
\hline Intracellular & 7 & PTPLAD1, RAB27A, PSEN1, ARF4 & CNOT8, SRI, CAPN2 \\
\hline $\begin{array}{l}\text { Intracellular } \\
\text { membrane-bound } \\
\text { organelle }\end{array}$ & 6 & $\begin{array}{l}\text { TCL1, SPCS2, LRRC59, PLA2G4A, YBX1, } \\
\text { HSD3B1 }\end{array}$ & \\
\hline Membrane & 45 & $\begin{array}{l}\text { EMC4, MARCKS, ATP512, EWSR1, } \\
\text { BCL2L10, PTPLAD1, RAB27A, , SCAMP5, } \\
\text { STOM, PSEN1, TGM2, SPCS2, CAST, SYPL, } \\
\text { UNC80, CYB5R3, LRRC59, SSR3, CDS2, } \\
\text { ABCC6, CKAP4, UQCR10, TMEM14C, NNT, } \\
\text { CYP11A1, S100A8, VNN1, PLET1, } \\
\text { GRAMD1B, HSD3B1, TMEM141 }\end{array}$ & $\begin{array}{l}\text { ENO3, ALPPL2, S100A6, VMN2R4, CABP7, FLNC, } \\
\text { GPR1, TMPRSS13, CAR2, MSN, SRI, NME2, CAPN2, } \\
\text { DPYSL2 }\end{array}$ \\
\hline $\begin{array}{l}\text { Mitochondrial } \\
\text { inner membrane }\end{array}$ & 10 & $\begin{array}{l}\text { ATP5J2, PSEN1, NDUFA8, CYB5R3, FDXR, } \\
\text { CDS2, UQCR10, NNT, CYP11A1 }\end{array}$ & CPS1 \\
\hline Mitochondrion & 24 & $\begin{array}{l}\text { ACOT11, ATP552, BCL2L10, PSEN1, TGM2, } \\
\text { NDUFA, CYB5R3, FDXR, , DXX1, HINT2, } \\
\text { CDS2, FXN, UQCR10, TMEM14C, NNT, } \\
\text { CYP11A1, HSD3B1 }\end{array}$ & $\begin{array}{l}\text { CPS1, HSPA1A, PRDX6, NME2, SHMT1, DPYSL2, } \\
\text { GSTZ1 }\end{array}$ \\
\hline Nucleosome & 10 & $\begin{array}{l}\text { HIST1H1C, HIST1H1B, HIST1H1A, H2AFY, } \\
\text { HIST1H1E, HIST1H1D, HIST1H3A }\end{array}$ & HIST2H2AB, HIST3Н2BA, HIST1H2AH \\
\hline Nucleus & 51 & $\begin{array}{l}\text { TCL1, DEK, EWSR1, BCLLL10, LRRFIP1, } \\
\text { PSEN1, CAST, LRRC59, TOP1, HIST1H1C, } \\
\text { NAP1L5, STAT5B, PARP12, PLA2G4A, } \\
\text { HIST1H1B, YBX1, HIST1H1A, H2AFY, } \\
\text { HIST1H1E, HIST1H1D, HIST1H3A }\end{array}$ & $\begin{array}{l}\text { S100A4, SFN, CPS1, S100A6, HIST2H2AB, KRT7, } \\
\text { KRT18, HIST3H2BA, S100A13, HSPA1A, HIST1H2AH, } \\
\text { TMSB4X, CACYBP, GTF3C2, POLR2I, PSMA4, CMTR1, } \\
\text { TAF15, RNF126, SF3A2, PDCD4, PIR, HDGF, MSN, } \\
\text { CNOT8, NUCKS1, TCF20, CAPN2, UROD, SHMT1 }\end{array}$ \\
\hline $\begin{array}{l}\text { Perinuclear } \\
\text { region of the } \\
\text { cytoplasm }\end{array}$ & 8 & PSEN1, PLA2G4A, YBX1 & S100A4, S100A6, S100A13, HSPA1A, NME2 \\
\hline $\begin{array}{l}\text { Plasma } \\
\text { membrane }\end{array}$ & 24 & $\begin{array}{l}\text { EWSR1, SCAMP5, STOM, PSEN1, TGM2, } \\
\text { ABCC6, MYO1B, ARF4, CKAP4, S100A8, } \\
\text { VNN1, PLET1 }\end{array}$ & $\begin{array}{l}\text { ALPPL2, S100A6, VMN2R4, CABP7, FLNC, GPR1, } \\
\text { CAR2, MSN, SRI, NME2, CAPN2, ITIH4 }\end{array}$ \\
\hline Protein complex & 6 & PSEN1 & CPS1, TTR, HSPA1A, ALB, DPYSL2 \\
\hline
\end{tabular}

form NADH. CYB5R3, which is upregulated in diabetic oocytes, uses NADH to desaturate and elongate fatty acids. Moreover, HSD3B1 and PARP12, which are also upregulated in diabetic oocytes, use NAD+ to catalyze hormonal steroid synthesis and vitamin B3 (niacin) synthesis, respectively. The upregulation of CYB5R3, HSD3B1, and PARP12 likely results in increased consumption of NAD+ in diabetic oocytes. In addition, the metabolic enzymes CPS1, NME2, and GSS (glutathione synthetase) were downregulated.

\section{Differential expression of histone variants in diabetic mouse oocytes}

In mammalian oocytes, enrichment of histone variants is essential for maintenance of chromatin structure and epigenetic reprogramming of early embryonic blastomeres [17, 18]. From the proteome data, we identified seven upregulated and three downregulated histone variants in diabetic mouse oocytes (Table 3). Of the seven upregulated histone variants, five were variants of histone H1 [HIST1H1C (H1.2), HIST1H1B, HIST1H1A (H1.1), HIST1H1E 


\section{Cellular Physiology Cell Physiol Biochem 2016;39:2320-2330

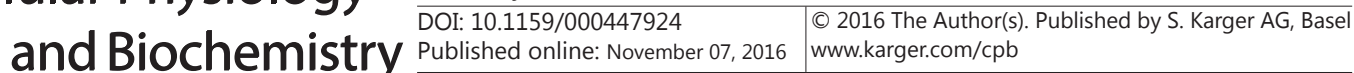 \\ Jiang et al.:Effect of Type I Diabetes on Mouse Oocytes and Protein Profile Changes}

Table 2. Biological pathways associated with differentially expressed proteins (DEPs)

\begin{tabular}{|c|c|c|c|}
\hline Biological Pathway & $\begin{array}{l}\text { Number of } \\
\text { DEPs }\end{array}$ & Upregulated Proteins & Downregulated Proteins \\
\hline Apoptosis & 7 & $\begin{array}{l}\text { EMC4, BCL2L10, PSEN1, CTSC, HINT2, } \\
\text { S100A8 }\end{array}$ & PDCD4 \\
\hline Cholesterol metabolism & 6 & $\begin{array}{l}\text { CYB5R3, FDXR, FDX1, APOC1, } \\
\text { CYP11A1 }\end{array}$ & APOA2 \\
\hline Lipid metabolism & 10 & $\begin{array}{l}\text { PTPLAD1, PLBD2, CYB5R3, FDXR, } \\
\text { FDX1, HINT2, CDS2, PLA2G4A, } \\
\text { CYP11A1 }\end{array}$ & PRDX6 \\
\hline Metabolic process & 10 & ACOT13, PLA2G4A, MYO1B, HSD3B1 & $\begin{array}{l}\text { ALPPL2, CPS1, PSPH, } \\
\text { PFKM, PRDX6, GSTZ1 }\end{array}$ \\
\hline Negative regulation of apoptosis & 8 & BCL2L10, PSEN1, STAT5B, FXN, YBX1 & KRT18, ALB, NME2 \\
\hline Nucleosome assembly & 11 & $\begin{array}{l}\text { HIST1H1C, NAP1L5, HIST1H1B, } \\
\text { HIST1H1A, H2AFY, HIST1H1E, } \\
\text { HIST1H1D, HIST1H3A }\end{array}$ & $\begin{array}{l}\text { HIST2H2AB, HIST3H2BA, } \\
\text { HIST1H2AH }\end{array}$ \\
\hline Oxidation-reduction & 11 & $\begin{array}{l}\text { NDUFA8, CYB5R3, FDXR, FDX1, FXN, } \\
\text { UQCR10, NNT, CYP11A1, HSD3B1 }\end{array}$ & PRDX6, PIR \\
\hline $\begin{array}{l}\text { Positive regulation of cell } \\
\text { proliferation }\end{array}$ & 6 & STAT5B, FXN, PLA2G4A, YBX1 & S100A13, CNOT8 \\
\hline $\begin{array}{l}\text { Positive regulation of } \\
\text { transcription from RNA } \\
\text { polymerase II promoter }\end{array}$ & 6 & STAT5B, YBX1 & $\begin{array}{l}\text { HDGF, IFNB1, NME2, } \\
\text { TCF20 }\end{array}$ \\
\hline Protein transport & 5 & RAB27A, SCAMP5, PSEN1, ARF4 & S100A13 \\
\hline Proteolysis & 10 & PSEN1, CTSC, SPCS2, SCPEP1, NAPSA & $\begin{array}{l}\text { PSMA4, TRY5, } \\
\text { TMPRSS13, CAPN2, } \\
\text { PRSS1 }\end{array}$ \\
\hline Signal transduction & 6 & FGB, STAT5B & $\begin{array}{l}\text { VMN2R4, KRT17, GPR1, } \\
\text { GKAP1 }\end{array}$ \\
\hline Steroid biosynthesis & 5 & $\begin{array}{l}\text { CYB5R3, FDX1, HINT2, CYP11A1, } \\
\text { HSD3B1 }\end{array}$ & \\
\hline Transcription, DNA-templated & 10 & EWSR1, LRRFIP1, STAT5B, YBX1 & $\begin{array}{l}\text { GTF3C2, POLR2I, PIR, } \\
\text { HDGF, CNOT8, TCF20 }\end{array}$ \\
\hline Transport & 17 & $\begin{array}{l}\text { ATP5J2, SCAMP5, NDUFA8, SYPL, } \\
\text { FDXR, FDX1, ABCC6, FXN, ARF4, } \\
\text { UQCR10, APOC1 }\end{array}$ & $\begin{array}{l}\text { S100A6, S100A13, TTR, } \\
\text { APOA2, ALB, LASP1 }\end{array}$ \\
\hline
\end{tabular}

Table 3. Genome (UCSC mm10) localization of the differentially expressed histone variants

\begin{tabular}{lllll}
\hline Histone Variant & Up- or Down-regulated & Chromosome (Strand) & Transcript Start Site & Transcript End Site \\
\hline HIST2H2AB & Down & Chr3 (+) & 96219915 & 96220353 \\
HIST3H2BA & Down & Chr11 (+) & 58948910 & 58949372 \\
HIST1H1B & Up & Chr13 (-) & 21779831 & 21780625 \\
HIST1H2AH & Down & Chr13 (-) & 22035121 & 22035643 \\
HIST1H1D & Up & Chr13 (+) & 23555031 & 23555807 \\
HIST1H1E & Up & Chr13 (-) & 23621776 & 23622558 \\
HIST1H1C & Up & Chr13 (+) & 23738806 & 23739531 \\
HIST1H3A & Up & Chr13 (-) & 23761853 & 23762386 \\
HIST1H1A & Up & Chr13 (+) & 23763667 & 23764412 \\
H2AFY & Up & Chr13 (-) & 56073621 & 56135550 \\
\hline
\end{tabular}

(H1.4), and HIST1H1D (H1.3)], whereas the other two were the H2A variant H2AFY (H2A.1) and the H3 variant HIST1H3A (H3.1). The three downregulated histone variants were variants of histone H2A: HIST2H2AB (H2A type 2-B), HIST3H2BA (H2B type 3-A), and HIST1H2AH (H2A type 1-H). In addition, TOP1 and HIST1H4A (histone H4) were upregulated in diabetic mouse oocytes. As most histone protein-coding regions cluster together in the mouse genome [19], we analyzed the genomic localizations of these histone variants. We found that HIST1H1B, HIST1H2AH, HIST1H1D, HIST1H1E, HIST1H3A, HIST1H1C, and HIST1H1A clustered on murine chromosome 13 (Table 3).

Effects of maternal diabetes on microtubule assembly and chromosome alignment during oocyte maturation

We further probed the function of proteins associated with chromatin assembly and DNA packaging, such as linker histones that can affect chromatin remodeling activity. Con- 


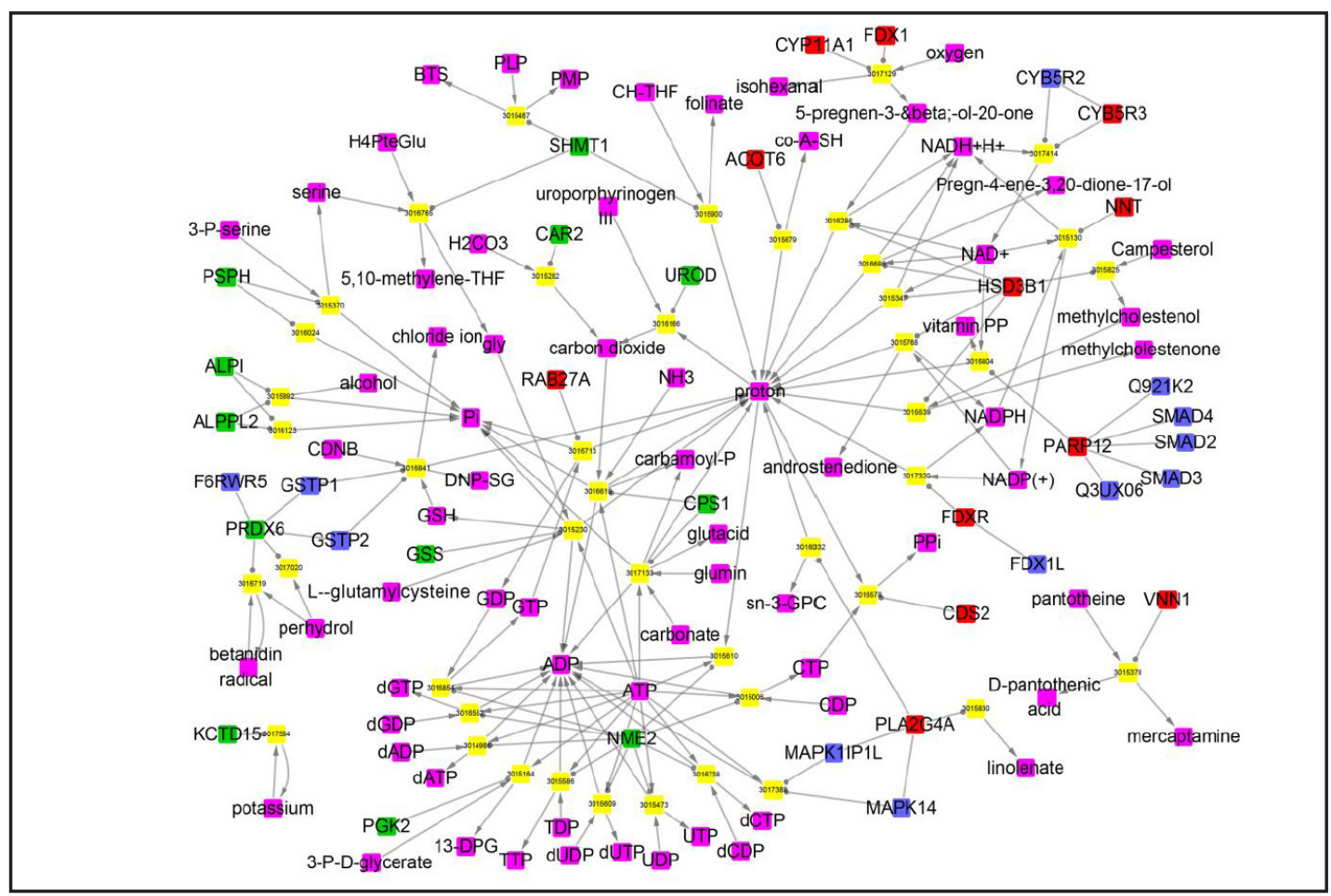

Fig. 4. Metabolic network of the differentially expressed proteins (DEPs) in diabetic oocytes. Pink, metabolites; yellow, reaction WID in BioWarehouse database; green/red, down/upregulated proteins in diabetic oocytes; gray, proteins that interact with the DEPs. Arrows show the direction of the enzymatic reaction.

Fig. 5. Diabetes-induced mitochondrial and spindle abnormalities in mouse oocytes. (A) Abnormal spindles in diabetic oocytes. (B) Abnormal mitochondria number and distribution in diabetic oocytes. Mitochondria were labeled with Mito-Tracker.

focal scanning revealed a typical barrel-shaped spindle and well-aligned chromosomes on the metaphase plate in control MII oocytes (normal rate: $91.4 \%, \mathrm{~N}=58$ ). In contrast, a significantly elevated number of diverse malformed spindles was observed in ovulated MII oocytes from diabetic mice (normal rate: $61.1 \% ; \mathrm{N}=54 ; \mathrm{p}<0.01$ ). The rate of chromosome misalignment was also significantly increased in oocytes from diabetic mice, as characterized by the displacement of chromosomes from the equator (Fig. 5A). These results suggest

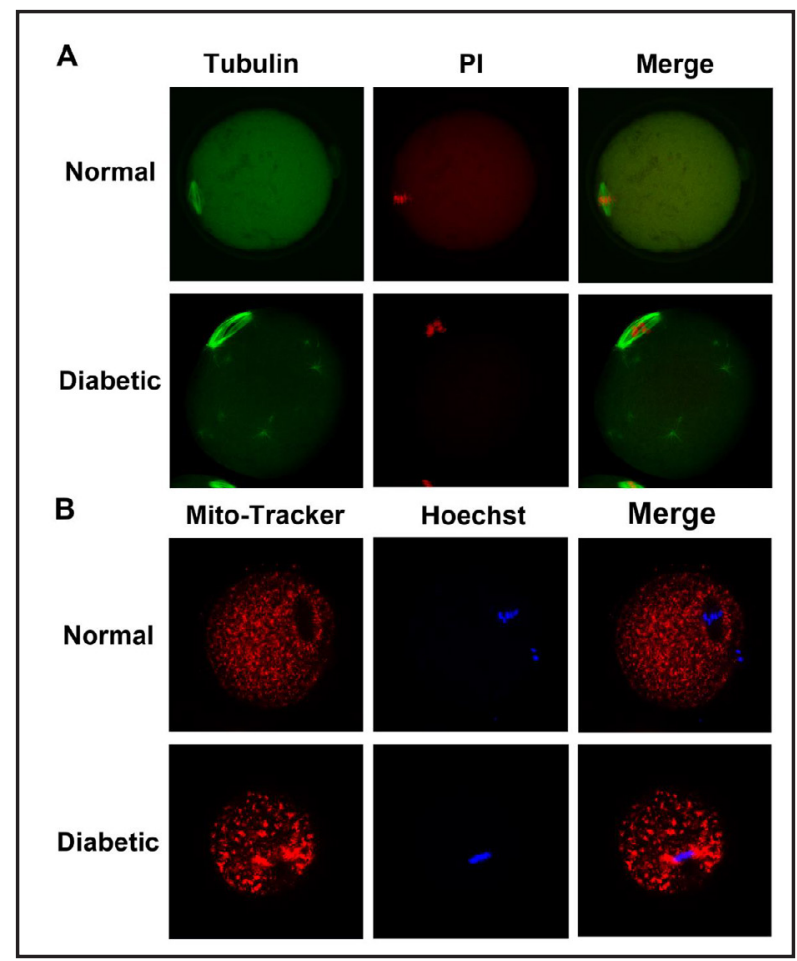

that maternal diabetes induces spindle defects and causes abnormal chromosome alignment in oocyte meiosis via modulation of protein expression.

\section{KARGER}




\section{Cellular Physiology Cell Physiol Biochem 2016;39:2320-2330 and Biochemistry Published online: November 07, $2016 \quad \begin{aligned} & \text { DOI: } 2016 \text { The Author(s). Published by S. Karger AG, Basel } \\ & \text { www.karger.com/cpb }\end{aligned}$ \\ Jiang et al.:Effect of Type I Diabetes on Mouse Oocytes and Protein Profile Changes}

Effects of maternal diabetes on the spatial remodeling of mitochondria during oocyte maturation

To further determine the function of key proteins associated with mitochondrial metabolism, such as FDXR and NNT, MII oocytes were collected from control and diabetic mice to determine the mitochondrial localization and for visualization of chromosomes. Mitochondrial distribution patterns were evaluated using fluorescence microscopy. Among control oocytes, $75.5 \%(\mathrm{~N}=53)$ possessed normal mitochondria; however, only $36.0 \%(\mathrm{~N}=$ $50)$ of diabetic oocytes had normal mitochondria $(\mathrm{p}<0.01)$. When compared with the control group, the diabetic group was found to have a reduced overall number of mitochondria, and the mitochondrial distribution was heterogeneous (Fig. 5B). Our results suggest that maternal diabetes causes abnormal mitochondrial distribution during oocyte maturation as a result of altered protein expression.

\section{Discussion}

Understanding how type I diabetes affects the oocyte proteome, and therefore female reproduction and embryonic development, may facilitate the identification of novel treatments and preventative measures for this disease or innovative ways to assist reproduction in affected women. Type I diabetes induces ROS accumulation and subsequently triggers cell dysfunction [20]. Insulin resistance is thus likely to increase ROS levels in oocytes [21]. Our results revealed downregulation of GSS in diabetic oocytes, which is expected to lead to decreased production of GSH. In contrast, increased levels of mitochondrial proteins are predicted to result in increased ROS production; hence, oxidative stress is a critical factor in the metabolism of diabetic oocytes. Previous reports have shown that glycolysis is blocked during oocyte maturation and early embryo development [22]. Moreover, production of NADPH is not affected by the pentose phosphate pathway in unfertilized oocytes [23]. In addition, lactate and pyruvate can respectively increase and decrease NAD(P)H levels [23]. NADPH is a substrate for GSH production and essential for controlling ROS levels in oocytes. Further research is needed to explore whether or not lactate supplementation and decreasing pyruvate levels could control ROS levels, leading to a reduction of oxidative stress in diabetic oocytes. Emodin is one of the major components of Rheum palmatum. It could effect on high glucose induced-podocyte mesenchymal transition by reducing oxidative stress which give us a potential clue to against free radical damage in diabetic oocytes [24].

At present, more and more people pay attention to the relationship between diabetes and epigenetics (DNA methylation, noncoding RNAs, nucleosome remodeling and histone modifications). We hypothesized that the phenotype transmission from parents to offspring is associated with the change of histone modification in oocytes of maternal diabetes.

The linker histone $\mathrm{H} 1$ has multiple effects on chromatin. Linker histones are critical for chromatin compaction and control nucleosome repeat length [25]. Furthermore, linker histones can alter the chromatin remodeling activity of ATP-dependent chromatin remodeling enzymes [26] and typically inhibit gene expression; however, they can also specifically activate the expression of certain genes [27]. In Xenopus laevis oocytes, histone $\mathrm{H} 1$ variant B4 participates in sperm chromatin remodeling [28], and similar functions have been observed for its mammalian homologue, H1 foo [29]. In the present study, we identified five linker $\mathrm{H} 1$ histone variants that were upregulated in diabetic oocytes and may thus influence chromatin structure in these cells. Alterations in the expression of these maternal linker histones could also affect the development of early embryos. Recently, Shinagawa et al [30]. showed that histone variants enriched in oocytes are essential for reprogramming of early embryonic blastomeres, and that HIST1H2AA and HIST1H2BA are associated with paternal genome activation in zygotes. Therefore, the downregulation of histone $\mathrm{H} 2$ variants in diabetic oocytes observed in the present study could impair the activation of the zygotic genome. Additionally, a core histone $\mathrm{H} 2$ variant, H2AFY, was upregulated in diabetic oocytes. $\mathrm{H} 2 \mathrm{AFY}$ prevents genome reprogramming, and its absence is required for early embryonic 


\section{Cellular Physiology Cell Physiol Biochem 2016;39:2320-2330 \begin{tabular}{ll|l} 
and Biochemistry Published online: November 07, 2016 & $\begin{array}{l}\text { (c) } 2016 \text { The Author(s). Published by S. Karger AG, Basel } \\
\text { www.karger.com/cpb }\end{array}$ \\
\hline
\end{tabular} \\ Jiang et al.:Effect of Type I Diabetes on Mouse Oocytes and Protein Profile Changes}

development [31]. Thus, the observed upregulation of H2AFY in diabetic oocytes may be predicted to impair embryonic development. Histone H3.3 is essential for oocyte and zygote reprogramming and for rRNA transcription in zygotes [32]; however, HIST1H3A is expressed at very low levels in MII oocytes and in the early embryonic stages. HIST1H3A does not incorporate into chromatin when it is present at low levels [33]; hence, the significant upregulation of HIST1H3A in diabetic oocytes observed in the present study may also impair zygotic genome reprogramming.

During gestation, metabolic needs significantly increases. Failure of meeting these requirements may result in GDM [34], Diabetes affect the ovulation maybe by hypothalamicpituitary axis. This study demonstrates changes in metabolic processes and histone variants in diabetic oocytes, leading to impaired oocyte quality and early embryonic development. Therefore, when oocytes from women with diabetes are used for assisted reproduction, methods to reduce ROS levels and expression of histone variants should be considered. In addition, the proteins identified in this study may serve as markers whose expression could be evaluated in the first or second polar bodies for assessment of oocyte quality.

In summary, these results illustrate potential targets and methods for improving diabetic oocyte quality and preventing subfertility in women with type I diabetes undergoing assisted reproduction. These results characterize the effects of diabetes on reproduction in an animal model, and further studies in humans are warranted.

\section{Abbreviations}

GDM (Gestational diabetes mellitus); COC (cumulus oocyte complex); DEP (differentially expressed protein); ER (endoplasmic reticulum); GSH (glutathione); hCG (human chorionic gonadotropin); iTRAQ (isobaric tags for relative and absolute quantitation); MII (metaphase II); PBS (phosphate-buffered saline); PMSG (pregnant mare serum gonadotropin); ROS (reactive oxygen species); STZ (streptozotocin).

\section{Acknowledgements}

This work was supported by Grants from the National Natural Science Foundation of China (NSFC81274041, NSFC81273995) and the International Cooperation Projects of MOE (2011DFA30920) and Construction project of Beijing [1000062520025].

\section{Disclosure Statement}

The authors declare no commercial or financial conflict of interest.

\section{References}

1 Li J, Song L, Zhou L, Wu J, Sheng C, Chen H, Liu Y, Gao S, Huang W: A MicroRNA Signature in Gestational Diabetes Mellitus Associated with Risk of Macrosomia. Cell Physiol Biochem 2015;37:243-252.

2 Ma JY, Li M, Ge ZJ, Luo Y, Ou XH, Song S, Tian D, Yang J, Zhang B, Ou-Yang YC, Hou Y, Liu Z, Schatten H, Sun QY: Whole transcriptome analysis of the effects of type I diabetes on mouse oocytes. PLoS One 2012;7:e41981.

3 Wang Q, Chi MM, Moley KH: Live imaging reveals the link between decreased glucose uptake in ovarian cumulus cells and impaired oocyte quality in female diabetic mice. Endocrinology 2012;153:1984-1989.

4 Moley K H, Vaughn, W K, DeCherney, A H \& Diamond, M P: Effect of diabetes mellitus on mouse preimplantation embryo development. J Reprod Fertil 1991;93:325-332. 


\section{Cellular Physiology Cell Physiol Biochem 2016;39:2320-2330

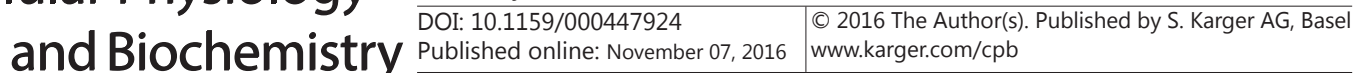 \\ Jiang et al.:Effect of Type I Diabetes on Mouse Oocytes and Protein Profile Changes}

5 Ge ZJ, Liang XW, Guo L, Liang QX, Luo SM, Wang YP, Wei YC, Han ZM, Schatten H, Sun QY: Maternal Diabetes Causes Alterations of DNA Methylation Statuses of Some Imprinted Genes in Murine Oocytes. Biol Reprod 2013;88:118-119.

6 Shi Z, Zhao C, Long W, Ding H, Shen R: Microarray Expression Profile Analysis of Long Non-Coding RNAs in Umbilical Cord Plasma Reveals their Potential Role in Gestational Diabetes-Induced Macrosomia. Cell Physiol Biochem 2015;36:542-554.

7 Liu L, Zhang X, Rong C, Rui C, Ji H, Qian YJ, Jia R, Sun L: Distinct DNA methylomes of human placentas between pre-eclampsia and gestational diabetes mellitus. Cell Physiol Biochem 2014;34:1877-1889.

8 Oh B, Hwang S, McLaughlin J, Solter D, Knowles BB: Timely translation during the mouse oocyte-to-embryo transition. Development 2000;127:3795-3803.

9 Bonnevie-Nielsen V, Steffes MW, Lernmark A: A major loss in islet mass and B-cell function precedes hyperglycemia in mice given multiple low doses of streptozotocin. Diabetes 1981;30:424-429.

10 Dankert D, Demond H, Trapphoff T, Heiligentag M, Rademacher K, Eichenlaub-Ritter U, Horsthemke B, Grümmer R: Pre- and postovulatory aging of murine oocytes affect the transcript level and poly(A) tail length of maternal effect genes. PLoS One 2014;9:e108907.

11 Jiang GJ, Ma JY, Zhang GL, Mo FF, Zhang DW, Gao SH, Li XL: Protein profiling the differences between diabetic and normal mouse cumulus cells. Mol Reprod Dev 2014;81:1080-1085.

12 Croft D, O'Kelly G, Wu G, Haw R, Gillespie M, Matthews L, Caudy M, Garapati P, Gopinath G, Jassal B, Jupe S, Kalatskaya I, Mahajan S, May B, Ndegwa N, Schmidt E, Shamovsky V, Yung C, Birney E, Hermjakob H, D'Eustachio P, Stein L: Reactome: a database of reactions, pathways and biological processes. Nucleic Acids Res 2011;39(Database issue):691-697.

13 Lee TJ, Pouliot Y, Wagner V, Gupta P, Stringer-Calvert DW, Tenenbaum JD, Karp PD: BioWarehouse: a bioinformatics database warehouse toolkit. BMC Bioinformatics 2006;7:1-14.

14 Cline MS, Smoot M, Cerami E, Kuchinsky A, Landys N, Workman C, Christmas R, Avila-Campilo I, Creech M, Gross B, Hanspers K, Isserlin R, Kelley R, Killcoyne S, Lotia S, Maere S, Morris J, Ono K, Pavlovic V, Pico AR, Vailaya A, Wang PL, Adler A, Conklin BR, Hood L, Kuiper M, Sander C, Schmulevich I,Schwikowski B, Warner GJ, Ideker T, Bader GD: Integration of biological networks and gene expression data using Cytoscape. Nat Protoc 2007;2:2366-2382.

15 Dumollard R, Ward Z, Carroll J, Duchen MR: Regulation of redox metabolism in the mouse oocyte and embryo. Development 2007;134: 455-465.

16 Balaban RS1, Nemoto S, Finkel T: Mitochondria, Oxidants, and Aging. Cell 2005;120:483-495.

17 Shinagawa T, Takagi T, Tsukamoto D, Tomaru C, Huynh LM, Sivaraman P, Kumarevel T, Inoue K, Nakato R, Katou Y, Sado T, Takahashi S,Ogura A, Shirahige K, Ishii S: Histone Variants Enriched in Oocytes Enhance Reprogramming to Induced Pluripotent Stem Cells. Cell Stem Cell 2014;14:217-227.

18 Hayakawa K, Ohgane J, Tanaka S, Yagi S, Shiota K: Oocyte-specific linker histone H1foo is an epigenomic modulator that decondenses chromatin and impairs pluripotency. Epigenetics 2012;7:1029-1036.

19 Marzluff WF, Gongidi P, Woods KR, Jin J, Maltais LJ: The human and mouse replication-dependent histone genes. Genomics 2002;80: 487-498.

20 Amaral S, Oliveira PJ, Ramalho-Santos J: Diabetes and the impairment of reproductive function: possible role of mitochondria and reactive oxygen species. Curr Diabetes Rev 2008;4:46-54.

21 Ou XH, Li S, Wang ZB, Li M, Quan S, Xing F, Guo L, Chao SB, Chen Z, Liang XW, Hou Y, Schatten H, Sun QY: Maternal insulin resistance causes oxidative stress and mitochondrial dysfunction in mouse oocytes. Hum Reprod 2012;27:2130-2145.

22 Barbehenn EK, Wales RG, Lowry OH: The explanation for the blockade of glycolysis in early mouse embryos. Proc Natl Acad Sci USA 1974;71:1056-1060.

23 Dumollard R, Duchen M, Carroll J: The Role of Mitochondrial Function in the Oocyte and Embryo. Curr Top Dev Biol 2007;77:21-49.

24 Chen T, Zheng LY, Xiao W, Gui D, Wang X, Wang N: Emodin ameliorates high glucose induced-podocyte epithelial-mesenchymal transition in-vitro and in-vivo. Cell Physiol Biochem 2015;35:1425-1436.

25 Bednar J, Horowitz RA, Grigoryev SA, Carruthers LM, Hansen JC, Koster AJ, Woodcock CL: Nucleosomes, linker DNA, and linker histone form a unique structural motif that directs the higher-order folding and compaction of chromatin. Proc Natl Acad Sci USA 1998;95:14173-14178. 


\section{Cellular Physiology Cell Physiol Biochem 2016;39:2320-2330 \begin{tabular}{ll|l} 
and Biochemistry 10.1159/000447924 & $\begin{array}{l}\text { O 2016 The Author(s). Published by S. Karger AG, Basel } \\
\text { Puww.karger.com/cpb }\end{array}$ \\
\cline { 2 - 3 }
\end{tabular}}

26 Horn PJ, Carruthers LM, Logie C, Hill DA, Solomon MJ, Wade PA, Imbalzano AN, Hansen JC, Peterson CL.: Phosphorylation of linker histones regulates ATP-dependent chromatin remodeling enzymes. Nat Struct Biol 2002;9:263-267.

27 Shen X, Gorovsky MA: Linker histone H1 regulates specific gene expression but not global transcription in vivo. Cell 1996;86:475-483.

28 Dimitrov S, Dasso MC, Wolffe AP: Remodeling sperm chromatin in Xenopus laevis egg extracts: the role of core histone phosphorylation and linker histone B4 in chromatin assembly. J Cell Biol 1994;126:591-601.

29 Becker M, Becker A, Miyara F, Han Z, Kihara M, Brown DT, Hager GL, Latham K, Adashi EY, Misteli T: Differential In Vivo Binding Dynamics of Somatic and Oocyte-specific Linker Histones in Oocytes and During ES Cell Nuclear Transfer. Mol Biol Cell 2005;16:3887-3895.

30 Shinagawa T, Takagi T, Tsukamoto D, Tomaru C, Huynh LM, Sivaraman P, Kumarevel T, Inoue K, Nakato R, Katou Y, Sado T, Takahashi S,Ogura A, Shirahige K, Ishii S: Histone variants enriched in oocytes enhance reprogramming to induced pluripotent stem cells. Cell Stem Cell 2014;14:217-227.

31 Nashun B, Yukawa M, Liu H, Akiyama T, Aoki F: Changes in the nuclear deposition of histone H2A variants during pre-implantation development in mice. Development 2010;137:3785-3794.

32 Lin CJ, Koh FM, Wong P, Conti M, Ramalho-Santos M: Hira-Mediated H3.3 Incorporation Is Required for DNA Replication and Ribosomal RNA Transcription in the Mouse Zygote. Dev Cell 2014;30:268-279.

33 Kawamura M, Akiyama T, Tsukamoto S, Suzuki MG, Aoki F: The expression and nuclear deposition of histone H3.1 in murine oocytes and preimplantation embryos. J Reprod Dev 2012;58:557-562.

34 Li J, Ying H, Cai G, Guo Q, Chen L: Pre-Eclampsia-Associated Reduction in Placental Growth Factor Impaired Beta Cell Proliferation Through PI3k Signalling. Cell Physiol Biochem 2015;36:34-43. 